\title{
MODELLING A SNOWDRIFT BY MEANS OF ACTIVATED CLAY PARTICLES
}

\author{
by \\ YUtAKa ANNo \\ Construction Machinery Institute of Hokkaido Development Bureau, Higashi 2-jo, \\ 8-chome, Tsukisamu, Toyohiraku, Sapporo, Japan \\ Present address: Cold Regions Research and Engineering Laboratory, \\ Hanover, New Hampshire 03755-1290, USA
}

\section{ABSTRACT}

This paper presents a small scale modelling of a snowdrift using activated clay particles.

Characteristic properties of activated clay particles, which are different from model snow particles proposed previously by other investigators, are fineness, high angle of repose and wide range of cohesion. Such properties may provide a similitude of a snowdrift and the phenomena caused by wet snow particles in a small scale model.

Experimental results presented in this paper show that activated clay particles are the most suitable substitute for natural snow particles in modelling, and indicate also the possibility of using them to model wet snow particles.

\section{INTRODUCTION}

Precise prediction of a shape of a snowdrift is very difficult, even one caused by a simple-shaped obstacle on the snow surface. Experiments simulating drifting snow thus become important, and many authors have attempted to model snowdrifts in wind tunnels, using reduced-scale models of such structures as snow fences and forests. Wind tunnels, in which model weather conditions are easily controlled, are invaluable provided that a suitable material is available as a substitute for natural snow.

Experiments using model snows have included the following: Finney (1939) used balsa sawdust and mica flakes; Kuroda and Kinosita (1940), Imai (1949) and Tanifuji and Ogawa (1952) used magnesium carbonate powder; Shiotani and Arai (1950) used aluminium oxide powder; Strom and Kelly (1962) used crystalline borax; and Iversen (1980) used fine glass beads. Of these, the powders except glass beads seemed to be less suitable in small scale modelling, in which the scale ratios between models and their prototypes were 1:100 to $1: 500$, because they easily cohere and turn to coarse granules, with a broad range of size distribution. Since the size of a model snow fence or snow forest is restricted by the dimensions of the wind tunnel used, it is desirable to use fine and less cohesive particles to represent the drifting natural snow.

In his comprehensive review Radok (1977) stated that modelling the basic snow processes such as sintering and cornice formation had not become practicable. Therefore, it has been considered diesirable to seek any material which can simulate the phenomena caused by the wide variation of cohesion of natural snow particles.

Activated clay is composed primarily of montmorillonite, whose surface is acidly activated by vitriolization. Dry activated clay particles are characterized by fineness and low cohesion, while wet particles have strong cohesion. They are thus the most suitable material for model snow particles.

This author has found accidentally that wet activated clay particles can simulate the formation of snow rollers, suggesting the possibility of modelling phenomena caused by wet snow particles. This paper presents the modelling procedure of a snowdrift formed around a snow fence, and the possibility of simulating wet snow particles using activated clay particles.

\section{MODELLING APPARATUS AND PROCEDURE}

Activated clay particles (Figure 1), mainly composed of montmorillonite, have a surface activated by vitriolization so that cations of the minerals are partly replaced by hydrogen ions. Moreover, the vitrolization changes a large number of the montmorillonite particles to silica gel particles, making the clay a kind of desiccative.

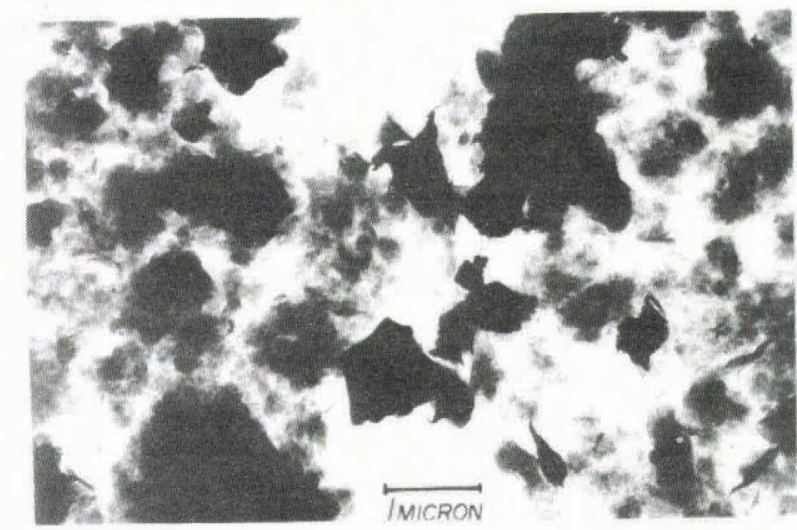

Fig.1. Photoelectron micrograph of activated clay particles.

Properties of the particles are as follows: the pure and bulk densities are $2.51 \mathrm{~g} / \mathrm{cm}^{3}$ and $0.65 \mathrm{~g} / \mathrm{cm}^{3}$, respectively; the specific surface area is $200-300 \mathrm{~m}^{2} / \mathrm{g}$; the angle of repose varies with the water content in a range of $45-52^{\circ}$ (Figure 2) roughly in agreement with the value of angle of repose of natural snow particles at low temperatures, measured by Kuroiwa and others (1956). Mode diameter of the clay particles measured statistically from Figure 1 is found to be 1.5 micrometers. Since the scale ratios between the model and the prototype obstruction are 1:100 to 1:500 in the present experiment, the diameter of 1.5 micrometers corresponds geometrically to that of natural snow particles, which ranges from 150 to 750 micrometers.

A wind tunnel of open-circuit type with a cross section of $80 \mathrm{~cm} \times 80 \mathrm{~cm}$ was used: Figure 3 shows the test section and the ejector of model snow particles. The particles were conveyed from an auto feeder to a nozzle through a hose by compressed air; then ejected into the air flow of the wind tunnel at a rate of $230 \mathrm{~g} / \mathrm{min}$. The ejection of model snow particles increased the turbulence level to about $10 \%$ at the height of $1 \mathrm{~cm}$ on the model snow surface, which is the same level as in the case of the natural wind (Tanifuji and Ogawa 1952).

Figure 4 shows a snow fence modelled on the scale of $1 / 300$, made of copper plate fixed upright at the base of rough-surfaced plywood. Consisting of 10 horizontal slats, this is a replica of a standard snow fence used in 
Hokkaido, with porosity of $18.4 \%$. The width of the model is $11 \mathrm{~mm}$, with clearance of $1.5 \mathrm{~mm}$ (one seventh of fence height) above the ground. In this experiment, 12 model fences were aligned transversely against air flow to form a single-row barrier. On a scale ratio of $1 / 300$, this represents a snow fence $3.45 \mathrm{~m}$ high.

The wind profile used in the modelling of a snowdrift (Figure 5) was measured upwind at a distance of $180 \mathrm{~mm}$ from the model fence with a hot-wire anemometer; distances smaller than this produced undesirable effects at the fence. The wind profile indicates a well-defined logarithmic distribution. Wind speed was maintained at $4.0 \mathrm{~m} / \mathrm{s}$ at a height of $1 \mathrm{~cm}$. Profiles of model snowdrifts were measured 10, 20, 30 and 40 minutes after the initiation of the modelling experiment. The wind speed used in the modelling of

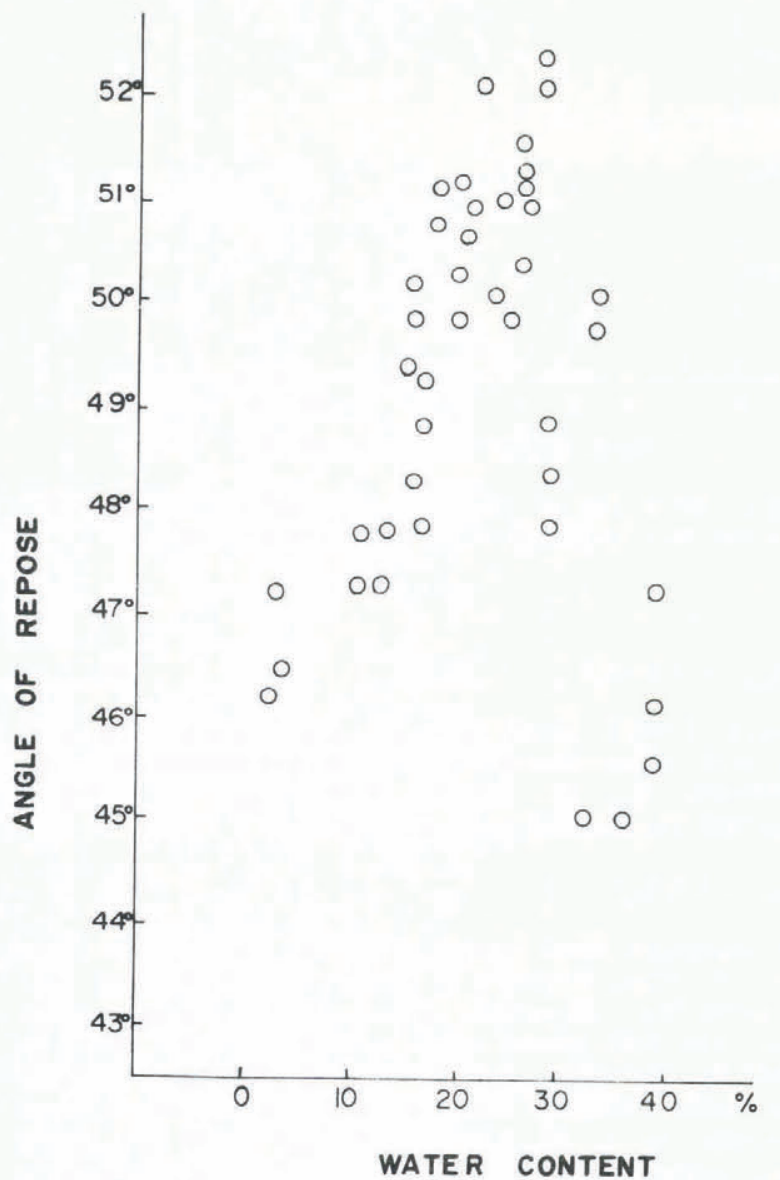

Fig.2. Angle of repose of activated clay particles versus their water contents.

\section{MODEL SNOW FENCE}

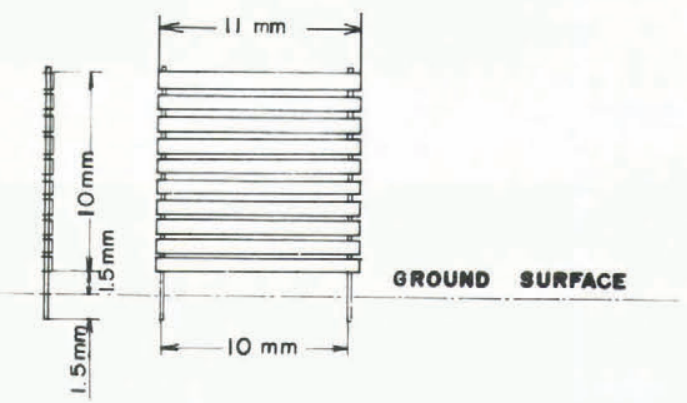

Fig.4. Model snow fence on the scale of $1 / 300$.

snow rollers was $2.5-3.0 \mathrm{~m} / \mathrm{s}$ at a height of $1 \mathrm{~cm}$, which was a little larger than the threshold value for movement of activated clay particles.

\section{MODELLING REQUIREMENTS}

Previous investigators chose the Froude number as the most appropriate similitude parameter for modelling a snowdrift (Iversen 1980). However, Anno (1984) reported that the matching of the Froude number between the model and its prototype was not appropriate for calculating the ratio of wind speed and storm duration between model and prototype; because the number expresses the ratio of inertia to gravity, and does not include the frictional force which has a large effect on saltated particles. He proposed that windspeed ratio and storm duration ratio between the model and its prototype should be estimated independently of each other from each similitude parameter.

$\mathrm{He}$ presented the following simple equation for approximate estimation of wind speed ratio at a reference height between the model and its prototype, stressing friction between snow particles and the snow surface.

$$
\mathrm{U}_{\mathrm{p}} / \mathrm{U}_{\mathrm{m}}=\left(\mathrm{A}_{\mathrm{m}} \cdot \mathrm{U}_{\mathrm{pt}}^{*}\right) /\left(\mathrm{A}_{\mathrm{p}} \cdot \mathrm{U}^{*}{ }_{\mathrm{mt}}\right)
$$

where $U$ is the wind speed at the reference height, $A$ is the coefficient of proportionality, $\mathrm{U}^{*}{ }_{\mathrm{t}}$ is the threshold friction speed, and $\mathrm{m}$ and $\mathrm{p}$ are subscripts denoting the model and the prototype respectively.

Anno estimated that $A_{p}$ was 0.040 , using data measured by Nishio and Ishida (1973), and that $A_{m}$ was 0.056 from the measurements in the wind tunnel when $U_{p}$ was the prototype wind speed at a height of $1 \mathrm{~m}$, and $\mathrm{U}_{\mathrm{m}}$ was the model wind speed at a height of $1 \mathrm{~cm}$. $\mathrm{He}$ also estimated that $\mathrm{U}^{*}{ }_{\mathrm{pt}}$ was $20 \mathrm{~cm} / \mathrm{s}$ since the threshold wind speed at a height of $1 \mathrm{~m}$ in Hokkaido was $5 \mathrm{~m} / \mathrm{s}$. $\mathrm{He}$ measured further that $\mathrm{U}^{*}$ was 112 $\mathrm{cm} / \mathrm{s}$ for activated clay particles. He then calculated that $\mathrm{U}_{\mathrm{p}} / \mathrm{U}_{\mathrm{m}}$, the ratio between the prototype wind speed at a height of $1 \mathrm{~m}$ and the model wind speed at a height of

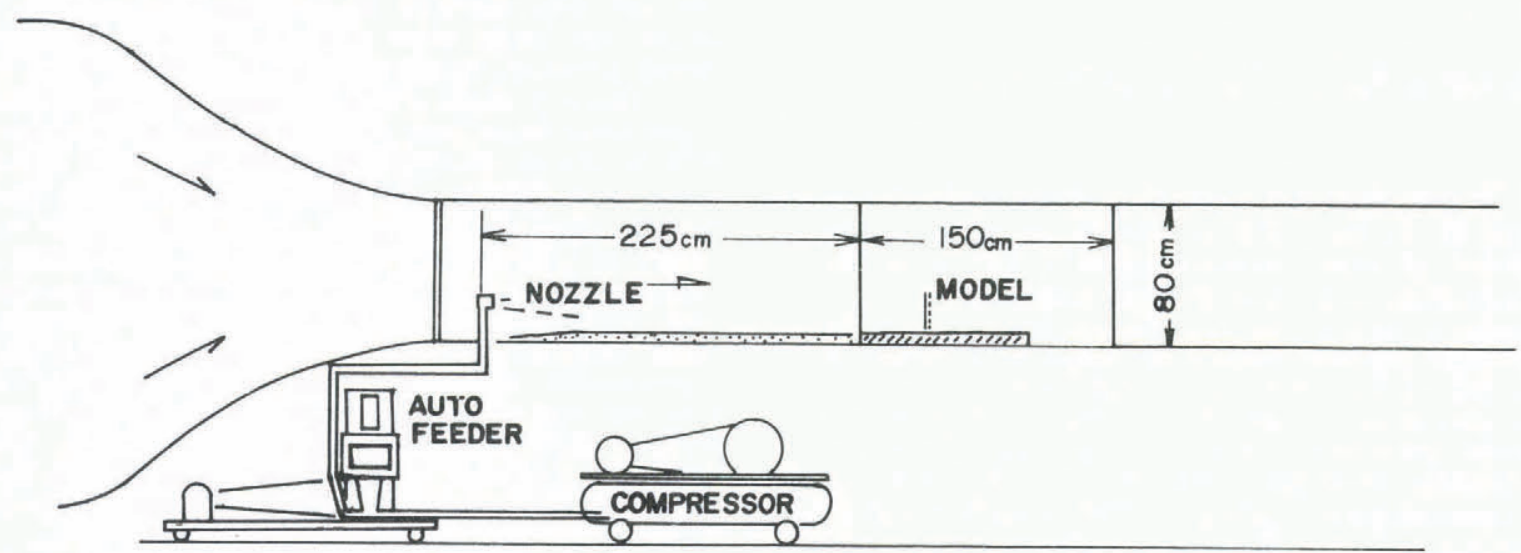

Fig.3. Testing section of the experimental wind tunnel used. 


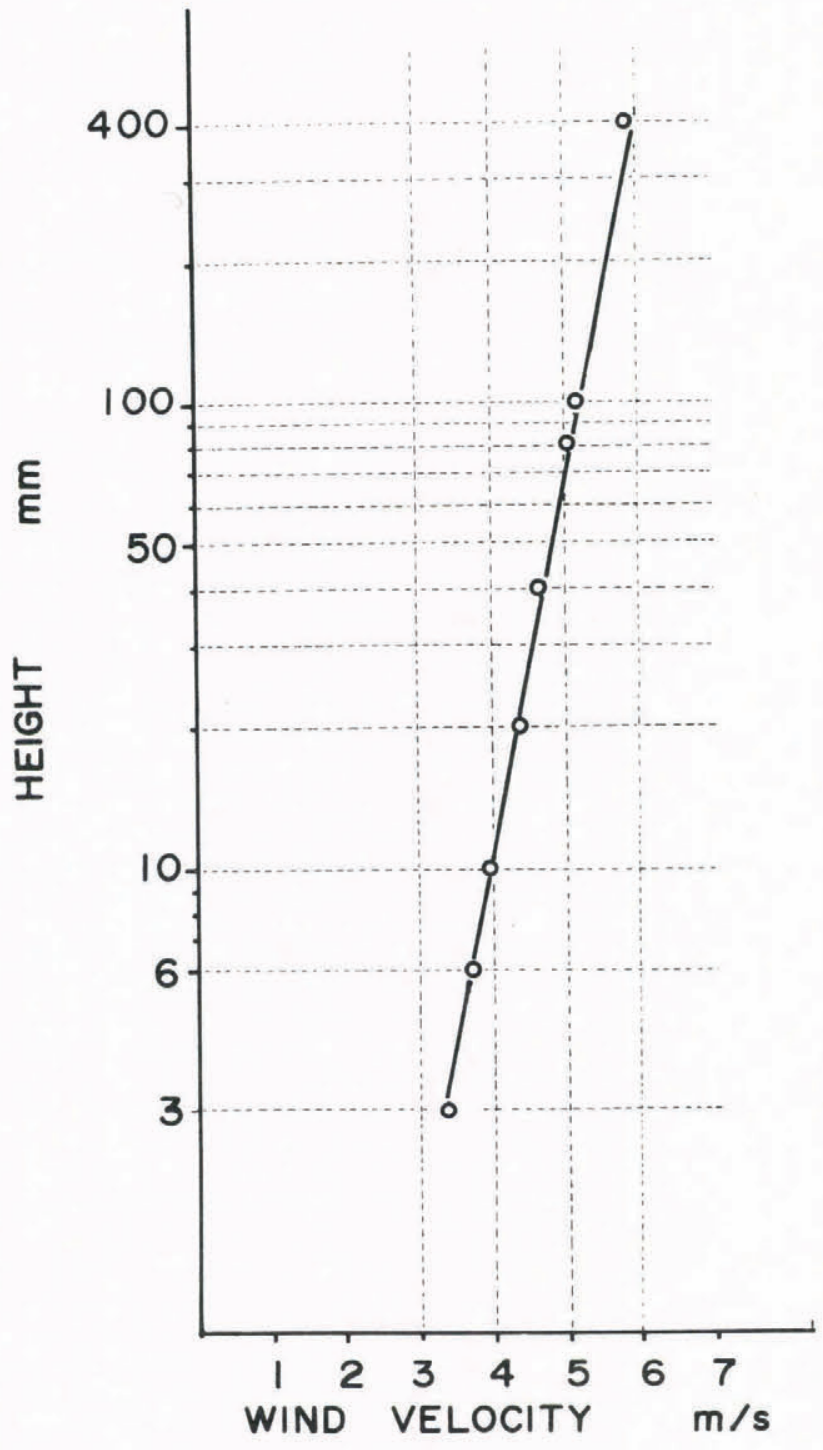

Fig.5. Wind profile used in the modeling of a snowdrift.

$1 \mathrm{~cm}$, was 2.46 from these values. From the wind speed ratio, 2.46 and the model wind speed at a height of 1 $\mathrm{cm}, 4 \mathrm{~m} / \mathrm{s}$, he estimated that the prototype wind speed was $9.84 \mathrm{~m} / \mathrm{s}$ at a height of $1 \mathrm{~m}$.

He also stated that the most reliable and practical estimation of the storm duration required in a model, in comparison to that of its prototype, would be obtained by comparing the volume of a leeward snowdrift between a model and its prototype by the following equation:

$$
\left(T_{p} \cdot Q_{p} \cdot \eta_{p}\right) /\left(\rho_{p} \cdot F_{w p}{ }^{2}\right)=\left(T_{m} \cdot Q_{m} \cdot \eta_{m}\right) /\left(\rho_{m} \cdot F_{w m}{ }^{2}\right)
$$

where $T$ is the storm duration, $Q$ is the snowdrift rate $(\mathrm{g} / \mathrm{m} \cdot \mathrm{min}), \mathrm{Fw}$ is the width of the fence $(\mathrm{m}), \rho$ is the bulk density of snow particles $\left(\mathrm{g} / \mathrm{cm}^{3}\right)$, and $\eta$ is the object's collection coefficient of snow particles.

Figure 6 shows the relation between the model snowdrift rate and the model wind speed at a height of $1 \mathrm{~cm}$ in the wind tunnel. The model snowdrift rate of activated clay particles ejected from the nozzle when the model wind speed was $4 \mathrm{~m} / \mathrm{s}$, is $36 \mathrm{~g} / \mathrm{m} \mathrm{min}$, in Figure 6. The model's collection coefficient is $10 \%$ from this author's measurement. $F_{w p} / F_{w m}$ is 300. Kobayashi (1972) measured $Q_{\text {max }}$, the maximum unit drift rate $(\mathrm{g} / \mathrm{m} \cdot \mathrm{min})$ of natural snow in Hokkaido, which was represented by the following equation:

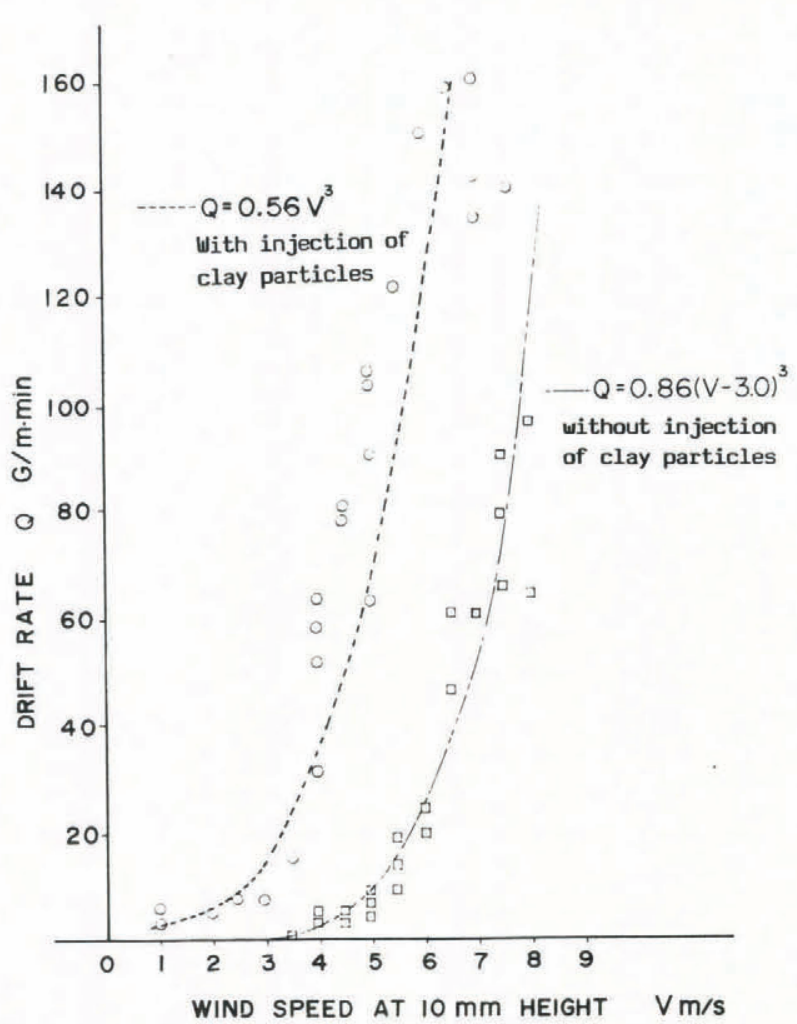

Fig.6. Drift rate of activated clay particles versus wind speed at a height of $1 \mathrm{~cm}$ in the wind tunnel.

$$
\mathrm{Q}_{\max }=1.8 \cdot \mathrm{U}_{\mathrm{p}}{ }^{3}
$$

Shiotani (1958) stated that $Q_{p}$, the average snowdrift rate $(\mathrm{g} / \mathrm{m} \cdot \mathrm{min})$, was about $70 \%$ of its maximum value. Therefore, $Q_{p}$ of natural snow must be roughly expressed by the following equation:

$$
\mathrm{Q}_{\mathrm{p}}=1.2 \cdot \mathrm{U}_{\mathrm{p}}{ }^{3}
$$

The prototype wind speed, $9.84 \mathrm{~m} / \mathrm{s}$, yields $Q_{p}=1,143$ $\mathrm{g} / \mathrm{m} \cdot \mathrm{min}$, from Equation 6. Uchiya (1967) reported that the prototype bulk density of a snowdrift behind a snow fence was $0.45 \mathrm{~g} / \mathrm{cm}^{3}$, and $\eta_{p}$ was $19 \%$ at Teshio in Hokkaido. Therefore, $\mathrm{T}_{\mathrm{p}} / \mathrm{T}_{\mathrm{m}}$ would be estimated as 1,032 . This storm duration ratio provides the prototype storm durations, as $7,14,21$ and 28 days from the model storm durations, which are $10,20,30$ and 40 minutes after the initiation of the modelling experiment respectively.

\section{RESULT AND DISCUSSION}

It is interesting to compare the experimentally obtained drift geometry of activated clay particles formed around the model snow fences with the geometry of a natural snowdrift formed around the prototype snow fence.

Figure 7 shows a model snowdrift formed around the model snow fence, and Figure 8 delineates a change in the cross section of the model snowdrift around the model snow fence as a function of time. As seen in this figure, 10 minutes after the initiation of the experiment a small mound of clay particles was formed on the leeside of the fence, with the crest located at a distance of about 3.2 times the height of the fence. The crest shifted toward the fence with the lapse of time. It shifted to a distance of approximately twice the height of the fence 40 minutes after the start of the experiment; then the model snowdrift attained equilibrium. Therefore, if the storm season is assumed to begin in the middle of December, the prototype snow fence would reach an equilibrium state in the middle of January.

Figure 9 illustrates the cross section of a prototype snowdrift around a prototype snow fence measured after a 


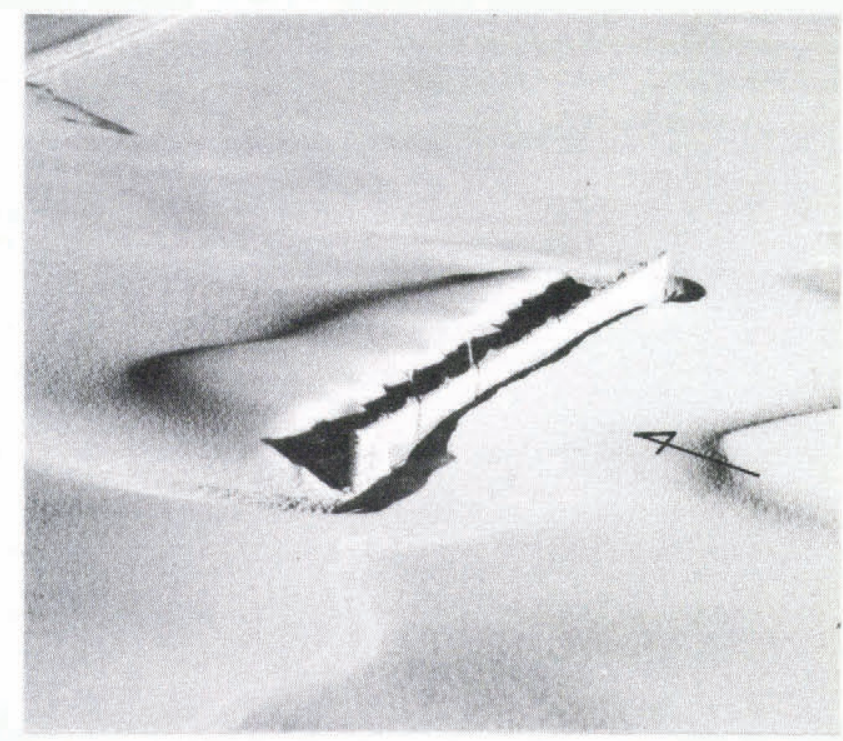

Fig.7. Model snowdrift formed around the model snow fence.

severe snowstorm by T Uchiya (1967) in Teshio, Hokkaido, on 16 January 1966. This fence was $3.3 \mathrm{~m}$ in height with horizontal slats, the bottom cleqarance of about $\mathrm{H} / 7$, and the same porosity as the model snow fence in Figure 4. The shape of this cross section represents an equilibrium state of the snowdrift formed around the snow fence. A comparison of the cross section of the model snowdrift 40 minutes after the initiation of the experiment in Figure 8 with that of natural snow in Figure 9 discloses only a minute difference in drift geometry.

Characteristics of activated clay particles different from those of model snow particles proposed previously by other investigators are fineness, high angle of repose and wide range of cohesion. These can be explained as follows: the strong surface electric charge caused by a large number of hydrogen ions and the dessication caused by a large number of silica gel particles prevent the clay particles from being granulated and coarsened when their water content is low. On the other hand, the particles cohere to each other with the chains of water molecules when their water content exceeds the dessicating ability of silica gel particles. The large surface area of dry activated clay particles and strong cohesion of the wet particles provide their high angle of repose.

The activated clay particles cohere only slightly unless their water content is high. It is necessary therefore, to

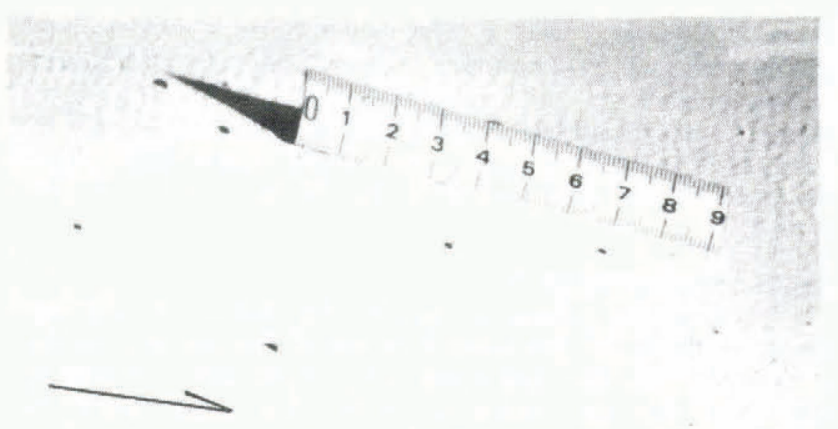

Fig.10. Model snow rollers formed by wet snow particles.

dessicate them before starting the modelling of newly fallen dry snow particles in a wind tunnel. However, wet activated clay particles make it possible to model the phenomenon caused by wet snow. For example, Figure 10 shows the model snow rollers formed on a flat model snow surface, whose prototype in the field is observed when a strong wind blows after a fall of wet snow. The model snow rollers, $0.5-3.0 \mathrm{~mm}$ in diameter, appear when moist activated clay particles $(12.5 \%$ in water content) are deposited, followed by an increase in wind speed to 2.5-3.0 $\mathrm{m} / \mathrm{s}$ at a height of $1 \mathrm{~cm}$ in the wind tunnel.

The geometrical correspondence in grain size between the clay particles and natural snow particles, as well as high angle of repose and wide range of cohesion, which is easily controlled by the water content, allows good visualization and simulation of a snowdrift, and of phenomena caused by wet snow particles.

\section{CONCLUSION}

A snowdrift modelled from activated clay particles is realistic in providing drift geometry and surface feature, as

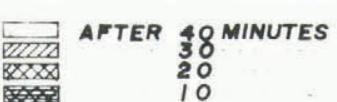

LEEWARD

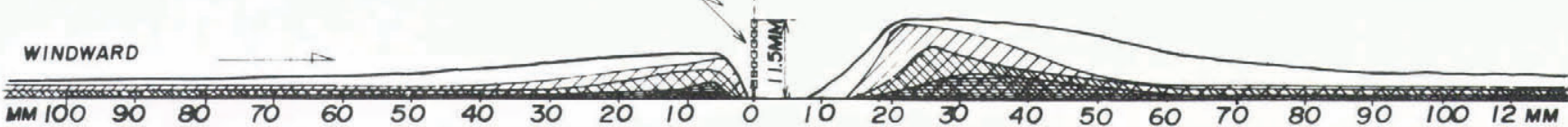

Fig.8. Change in the cross section of the model snowdrift formed around the model snow fence as a function of time.

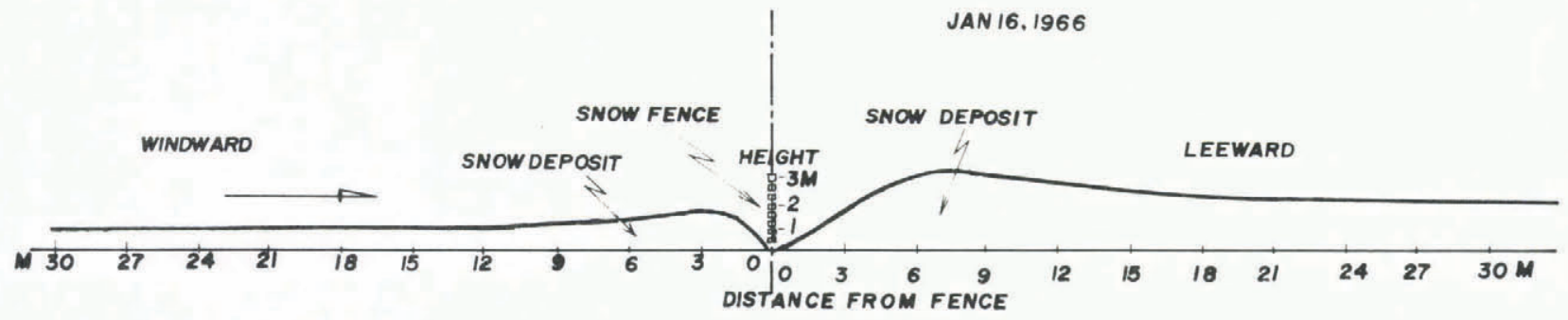

Fig.9. Cross section of a prototype snowdrift formed around the prototype snow fence measured by T. Uchiya (1967) in Teshio, Hokkaido, in January 1966. 
shown in Figures 7 and 8 . The results suggest that the use of the activated clay particles makes it possible to simulate precisely methods of preventing snowdrift formation. Moreover, the similitude of snow rollers shown in Figure 10 indicates that it is possible to simulate other basic snow processes of the kind which $U$ Radok pointed out in his review.

\section{ACKNOWLEDGEMENTS}

The author wishes to express his thanks to the late Dr D Kuroiwa, of Hokkaido Institute of Technology and Dr $J$ Dokoshi, of the Department of Agriculture, Hokkaido University. He also wishes to extend his hearty thanks to Dr M Kiya of the Department of Mechanical Engineering, Hokkaido University, for helpful suggestions relating to fluid dynamics. He is grateful to $\mathrm{Dr} M$ Mellor of CRREL for valuable suggestions and encouragement.

\section{REFERENCES}

Anno Y 1984 Requirements for modeling of a snowdrift.

Cold Regions Science and Technology 8(4): 241-252

Finney E A 1934 Snow control on the highway. Michigan Engineering Experiment Station, Bulletin 57

Imai I 1949 [Similarity rule in model experiments of a snowstorm]. Seppyo (Snow and Ice) 11(1): 14-16 (in Japanese).

Iversen J D 1980 Drifting snow similtiude-transport rate and roughness modeling. Journal of Glaciology 26(94): $393-403$

Kobayashi D 1972 Studies of snow transport in low-level drifting snow. Contributions from the Institute of Low Temperature Science, A, 24: 1-58

Kuroda K and Kinoshita, M 1940 [Report on experiments on a snowstorm in a wind tunnel]. Japan Snow and Ice Society, Paper 1: 144-158 (in Japanese)

Kuroiwa D, Mizuno $Y$ and Takeuchi M 1966 Micromeritical properties of snow. Proceedings of International Conference of Low Temperature Science $1-1(2): 751-772$

Radok U 1977 Snow drift. Journal of Glaciology 19(8): 123-139

Shiotani S and Arai H 1950 [Functions of snowdrift-preventing forest I.] Railway Administration Research Documents 7(19): 4-6 (in Japanese)

Strom G H and Kelly G R 1962 Scale model studies on snowdrifting. U.S. Army Snow, Ice and Permafrost Research Establishment Research Report 73

Tanifuji S and Ogawa T 1952 [Experimental study concerning prevention of a snowdrift on the road.] Seppyo (Snow and Ice) 13(6): 163-179; 14(1): 1-27 (in Japanese)

Uchiya T 1967 [Experiments in site of snow fences II.] Construction Machinery Engineering Plant of Hokkaido Development Bureau, Technical Research Report 3(38): 30-40 (in Japanese) 